\title{
Barriers to Immediate Post-Partum Intra-Uterine Contraceptive Device Uptake among Mothers Delivering at Meru Hospital
}

\author{
Consolata Kirigia*, Lucy Gitonga, Moses Mahugu Muraya \\ Chuka University, Chuka, Kenya \\ Email: *consolatakirigia@gmail.com
}

How to cite this paper: Kirigia, C., Gitonga, L. and Muraya, M.M. (2019) Barriers to Immediate Post-Partum Intra-Uterine Contraceptive Device Uptake among Mothers Delivering at Meru Hospital. Open Journal of Obstetrics and Gynecology, 9, 312-325. https://doi.org/10.4236/ojog.2019.93032

Received: January 30, 2019

Accepted: March 1, 2019

Published: March 4, 2019

Copyright () 2019 by author(s) and Scientific Research Publishing Inc. This work is licensed under the Creative Commons Attribution International License (CC BY 4.0). http://creativecommons.org/licenses/by/4.0/

\begin{abstract}
Global contraceptive use is at $64 \%$, Africa lagging behind at 33.4\%. Kenya has an unmet need for family planning at $23 \%$. Hormonal injections are the most used in Africa at 9.8\% and Intra-Uterine Contraceptive Devices at 3.8\%. Low uptake of 3.4\% was reported in Meru Hospital and lack of literature on immediate Post Partum Intra Uterine Contraceptive Device (PPIUCD) uptake. Immediate Post Partum Intra Uterine Contraceptive Device is a long acting reversible contraceptive device inserted into the uterus immediately within 48 hours after delivery. The objective was to assess Barriers to Immediate Post-Partum Intra-Uterine Contraceptive Device uptake among Mothers delivering in Meru Hospital. Descriptive research design was used and a population of 289 mothers was targeted. Sample size of 74 respondents was selected using simple random sampling. Questionnaires and interview schedules were used to collect data. The collected data were entered and analyzed using Statistical Package for Social Science windows version 23.0. Descriptive analysis was used to obtain frequencies and percentages. Chi-square was used to test the relationship of study variables and presented in tables. The qualitative data were analyzed thematically. The findings revealed that provider related barriers such as none provision of the services and untimely counseling for the insertion had the highest impact to low uptake (57\%). Clients lacked information where $68 \%$ reported that they were not counseled. Demographic and reproductive characteristics also played a role in low uptake. Using the chi square test, there was a significant relationship, $\mathrm{P}=0.001$ between young age of the mothers, unemployment (53\%), low parity (56\%) and low uptake. Preference for other alternative contraceptives (25.8\%) such as hormonal methods was a barrier to the uptake. Therefore, barriers to PPIUCD uptake are provider related, alternative methods of contraception and client related such as lack of information, unemployment, young age and low parity. The
\end{abstract}


findings will inform Meru hospital management on barriers to immediate PPIUCD uptake. The study recommends an investigation on why providers hinder PPIUCD uptake and create awareness on PPIUCD services to the community.

\section{Keywords}

Barriers, Post-Partum, Intra-Uterine, Contraceptives, Uptake

\section{Introduction}

Global stabilization of population depends on successful reduction of obstacles to contraception services [1]. The obstacles must be identified for effective eradication. Family planning (FP) services are educational, comprehensive medical or social activities which enable individuals, including minors to determine freely the number and spacing of their children and to select the means by which this may be achieved (World Health Organization (WHO), 2018). Family planning allows people to attain their desired number of children and determine the spacing of pregnancies. It is one of the four pillars of the Safe Motherhood Initiative and enshrined in health related Sustainable Development Goals (SDGs) to reduce maternal death in developing countries [2].

Two hundred and fourteen million women of reproductive age who want to avoid pregnancy in developing countries are not using a modern contraceptive method [3]. Contraception is the key to slowing unsustainable population growth and the resulting negative impact on the economy by having the desired number of children for every parent. In the Sub Sahara African, the contexts for population and family planning include weak policies supporting family planning and inadequate resources [4]. In contrast most countries in Africa, Latin America and Asia have strong policies that strongly support family planning programs in population control [4]. Global contraceptive use stands at $64 \%$, with Africa lagging behind at $33.4 \%$. The Pills and injections are the most commonly used in Africa at $8.7 \%$ and 9.8\%, respectively (United Nations Department of Economic and Social Affairs (UNDESA), 2015). Intra Uterine Contraceptive Device (IUCD) utilization is at $3.8 \%$ while implants are at $2.3 \%$ and male condoms at $2.1 \%$. Kenya has an unmet need for family planning at $23 \%$ (Kenya Demographic Health Survey (KDHS), 2014).

Despite PPIUCD having several benefits such as preventing unwanted pregnancies due to early resumption of sexual activities and unpredictable ovulation after delivery, its uptake is low. An uptake of as low as 3.4\% was reported in Meru Hospital, out of target of more than 50\%. The PPIUCD uptake was not well documented and there was little information on the factors that hinders its uptake. Moreover, studies on the use of immediate PPIUCD were limited in Kenya. The main objective of the study is to assess barriers to immediate Post 
Partum Intra Uterine Contraceptive Device uptake among mothers delivering in Meru Hospital. The specific objectives are;

1) To determine client related barriers to immediate Post Partum Intra Uterine Contraceptive Device uptake among mothers delivering in Meru Hospital

2) To establish provider related barriers to immediate Post Partum Intra Uterine Contraceptive Device uptake among mothers delivering in Meru Hospital

3) To analyze method related barriers to immediate Post Partum Intra Uterine Contraceptive Device uptake among mothers delivering in Meru Hospital

The research findings serve as the source of knowledge to inform the hospital management on significant barriers to immediate PPIUCD uptake. The report provides an evidence base in problem solving related to PPIUCD family planning method. This helps in planning for interventions to increase from the low uptake of 3.4\% to the hospital set target of $6 \%$ by the end of the year 2018 .

According to a study on impact of health education on unmet needs of contraception in urban slums of Chandigarh India, lack of awareness of contraception methods contributes to low uptake of PPIUCD. Awareness here means that the mothers did not hear or see any advertisement about FP in the last 6 months or did not participate in any educational session about FP during last 6 months hence contributing significantly to low contraception uptake [5]. Lack of knowledge was also evident in Nyanza western Kenya in a study by Pauline et al. [6] who found that lack of contraception awareness and low uptake is related to none visit to antenatal clinic where education on family planning is mostly done. Social demographic characteristic also contribute to low uptake. In a study on factors influencing contraceptive non-use among women of advanced reproductive age in Nigeria by Bola et al. [7] found that socio-demographic characteristics exert more influence on non-use. There was a significant relationship between non use and current young age where three-quarters of the non-users were 21 30 years old related to the desire to get children early in marriage. None use was significantly influenced by woman's occupation as a housewife [8] in Nyanza western Kenya in a study on overcoming barriers to family planning through integration. As well, other studies revealed that the contraceptive use was found higher among employed women (67\%) than that of unemployed women [9]. Reproductive characteristics of the mothers are some of the barriers to the uptake [10]. In a study of postpartum intrauterine contraceptive device acceptance between primiparous and multiparous women in a tertiary care centre, acceptance of PPIUCD was significantly higher in multiparous women than primiparous [10]. Number of living children, and child preference were found to be significantly associated with current use of contraception [9]. Cultural Norms, Myths, Concerns and Miss Conceptions are other barriers.

Having bad belief about FP, e.g. loop can penetrate the heart, injection can cause infertility, pills can cause cancer, child-bearing is more comfortable at younger age, non-traditional methods of FP can harm the woman's health, are 
all related to culture [7]. Similarly in a study on barriers to modern contraceptive uptake among young women in Kenya by Rhoune et al. [11], revealed the main barrier to be a misconception from social networks that modern family planning causes infertility. In a study on midwives' views on PPIUCD [12] at nine wells hospital Dundee U.K, Lack of provider confidence, training and experience on insertion of PPIUCD is evident. It is the responsibility of a health care provider to ensure men's active involvement in reproductive healthcare which has shown to be positively associated with maternal and child health outcomes.

According to a study on Barriers affecting utilization of family planning services among rural Egyptian women by Eltomy et al. [1], the study explored the various types of reported barriers for both the discontinued group and the non-users. Service provider's negative attitude, shortage of staffs, protocols requiring woman to be on her period to start hormonal or IUCD methods contributed to low uptake. Concerning barriers related to the method by Bola et al. [7] more than half of the women who had discontinued using contraception had a desire to have a more effective method. This could be due to past experience of failure of the method or the presence of side-effects.

\section{Methodology}

\subsection{Study Site}

Study was carried out in postnatal ward, maternity department of $\mathrm{MH}$ for a period of two months. The hospital is the main county referral hospital located in the urban part of the county at the outskirts of Meru town. Patients are referred from rural health facilities within the county for specialized services like obstetric and gynecological services and for attention by senior midwives among others. MH is a teaching hospital for students from various medical schools within the Mount Kenya region.

\subsection{Study Design}

A descriptive research design was used to determine answers to the study questions at $\mathrm{MH}$ in the months of June and July 2018. This was a social science research therefore need for descriptive answers to the study questions. The purpose of social science research is to explore, describe and explain a phenomenon [13].

\subsection{Population}

From the hospital records there were 5204 deliveries annually. This translated to an average of 14 deliveries daily. According to Kenya reproductive health care bill (2014), reproductive age starts from 15 - 49 years and have the right to consent willingly for their reproductive health services including minors. A Population of 289 delivering mothers who were admitted in maternity post-natal ward during the period of study in the months of June and July 2018 was targeted. 


\subsection{Sampling Procedure}

Due to few number of mothers inserted the device, a census was carried out for all mothers that were inserted. For non-inserted mothers group, a sample size of 74 respondents was used as a representative to the target population of 289 mothers. Respondents selection was done through simple random sampling procedure. The sample size was derived according to Nassiuma [14]. According to Nassiuma [14] coefficient of variation of at most $30 \%$ is acceptable in most surveys. In this study a coefficient of variation of $20 \%$ was used and a standard error of 0.02 .

Nassiuma [14] gives the formula as follows;

Sample size $n=\frac{N C^{2}}{C^{2}+(N-1) \mathrm{e}^{2}}$

where, $n=$ sample size

$N=$ population from which sample is obtained, 289

$C=$ coefficient of variance, $20 \%$

$e=$ standard error, 0.02

$$
\frac{289(0.2)^{2}}{0.2^{2}+(289-1) 0.02^{2}}
$$

$n=74$

\subsection{Inclusion and Exclusion}

Inclusion criteria depended on the mandatory characteristics that the subjects needed to have if they were to be included in the study. In this study the inclusion criteria was the mothers willing to participate in the study. Those who did not have the insertion and willing to participate were included to determine uptake barriers. Exclusion criteria were those characteristics that disqualified the subjects from inclusion in the study. In this study the exclusion criteria was those mothers who were not willing to participate in the study and those who had the insertion.

\subsection{Data Collection Procedure}

This study was carried out in postnatal ward, maternity department of $\mathrm{MH}$ for a period of two months. The Subjects consented before the interview and filled in the questionnaires with the assistance of the researcher where necessary. The consent followed a detailed explanation on the nature and purpose of the study. Data collection was done in a private side room or a screened bedside depending on the client's general condition.

\subsection{Data Collection Instruments}

Data collection was carried out using structured questionnaires as the primary tools and interview schedules to gather qualitative and quantitative data. The questionnaires were divided into sections. Section A gathered the information 
on social demographics, section $\mathrm{B}$ reproductive characteristics and $\mathrm{C}$ explored on other factors i.e. client, provider and method related barriers and facilitators respectively. Interview schedules had one section exploring on clients general perceptions regarding PPIUCD services. These form the effective means of measuring the barriers of PPIUCD method of family planning. Questionnaires were analyzed using Statistical Package for Social Science (SPSS) for windows version 23.0. Interview schedule helped the researcher to get more detailed information regarding PPIUCD uptake as a method of FP.

\subsection{Pretesting}

The data collection tools will be pretested at Embu level five hospital. The facility offers same services to mothers with similar characteristics to those in MH. Pretesting will be done in order to fish out wording issues and questions that are ambiguous and difficult to answer. $10 \%$ of the sample size will be interviewed during pretesting. This will also help the researcher estimate the length of time taken to fill one questionnaire and entire data collection period.

\subsection{Establishing Reliability and Validity}

Establishing reliability and validity is to determine repeatability and accuracy of data correction instruments respectively. To establish reliability, pretesting of the instruments was done using split-half reliability coefficient. To establish validity, a review of literature was done to compare and contrast the instruments with research findings from similar instruments in other studies. Moreover, consultations of experts from the department to judge and determine the completeness of the instruments was done.

\subsection{Data Analysis}

The collected data was entered and analyzed using statistical package for social science (SPSS) for windows version 23.0. Descriptive analysis was used to obtain frequencies and percentages. Chi-square was used to test the relationship of study variables. Interview schedules were analyzed thematically in relation to study objectives and the analyzed data presented in tables and narratives.

\section{Results and Discussions}

\subsection{Demographic and Reproductive Characteristics of Respondents}

Table 1 shows the demographic and reproductive characteristics of respondents. Majority were aged between 20 - 30 years (68\%), had low parity of 1 - 3 (56\%) and $(53 \%)$ were unemployed. Majority were married (55\%) and (59.5\%) were protestants.

\subsection{Age}

The mothers aged between 20 - 30 years had the highest number (68\%) of 
PPIUCD non uptake, followed by those above 30 years at 18\%, 15 - 19 years $9.5 \%$ and those below 15 years had the least number of uptake at $2.7 \%$. this coincides with a study on factors influencing contraceptive non-use among women of advanced reproductive age in Nigeria by Bola et al. [7] found that; Socio-demographic characteristics exert more influence on non-use. There was a significant relationship between non use and current young age, Three-quarters of the non-users were 21 - 30 years old related to the desire to get children early in marriage.

Table 1. Demographic characteristics of respondents.

\begin{tabular}{|c|c|}
\hline AGE GROUPS & PERCENTAGE \\
\hline Below 15 years & 2.7 \\
\hline $15-19$ years & 9.5 \\
\hline 20 - 30 years & 68.9 \\
\hline Above 30 years & 18.9 \\
\hline Total & 100.0 \\
\hline \multicolumn{2}{|l|}{ PARITY } \\
\hline None & 23.7 \\
\hline $1-3$ & 56.0 \\
\hline More than 3 & 20.3 \\
\hline Total & 100.0 \\
\hline \multicolumn{2}{|l|}{ EMPLOYMENT STATUS } \\
\hline salaried employment & 14.5 \\
\hline Unemployed & 53.0 \\
\hline Self employed & 31.1 \\
\hline Total & 100.0 \\
\hline \multicolumn{2}{|l|}{ RELIGION } \\
\hline Catholic & 21.6 \\
\hline Protestant & 59.5 \\
\hline Muslim & 6.8 \\
\hline Others & 8.1 \\
\hline None & 4.1 \\
\hline Total & 100.0 \\
\hline \multicolumn{2}{|l|}{ MARITAL STATUS } \\
\hline Married & 55.0 \\
\hline Single & 18.9 \\
\hline Separated/divorced & 14.9 \\
\hline Widowed & 10.8 \\
\hline Total & 100.0 \\
\hline
\end{tabular}




\subsection{Parity}

Most respondents were para $1-3,56 \%$. Para $0+0$ were $23.7 \%$, more than para 3 , were $20.3 \%$. This affirms that acceptance of PPIUCD was significantly higher in multiparous women than primiparous in a study of postpartum intrauterine contraceptive device acceptance between primiparous and multiparous women in a tertiary care centre [10]. Number of living children, and child preference were found to be significantly associated with current use of contraception [9].

\subsection{Employment Status}

Most non users were unemployed 53.0\%, followed by those who were self employed at $31.1 \%$, and the least number of non users had salaried employment at $14.5 \%$. This approves that non use was significantly influenced by woman's occupation as a housewife [7]. As well, other studies revealed that the contraceptive use was found higher among employed women (67\%) than that of unemployed women [9].

\subsection{Other Client, Provider and Method Related Barriers}

Most respondents as shown in Table 2 who were the non users $57.0 \%$ were not given any information on PPIUCD. 32.1\% were given information but refused to consent for insertion. $4.1 \%$ were informed and consented but the service was not offered to them. $4.1 \%$ had a problem therefore did not meet the insertion criteria. $2.7 \%$ consented, insertion done but unsuccessful while the other waited for the spouse to consult but did not come. It collaborates to a study on Barriers affecting utilization of family planning services among rural Egyptian women by Eltomy et al. [1], the study explored the various types of reported barriers for both the discontinued group and the non-users. Provider related barriers were reported barriers that lead to not using or discontinuation of FP methods which included service provider's negative attitude and shortage of staffs.

According to Table 3 the mothers who were given information on PPIUCD but did not consent for the services opted for alternative methods of family planning $25.8 \%$. 2.7\% had fears of myths and misconceptions, $2.7 \%$, refused to consent because of staff negative attitudes, poor and services. $2.7 \%$ refused to consent because they had previous bad experience and side effects on this type of method, $1.4 \%$ was not married therefore they did not need family planning methods and the other $1.4 \%$ was on the basis of religion. $77 \%$ did not refuse to consent for the insertion. Similar to a study concerning barriers related to the method by Bola et al. [7] more than half of the women who had discontinued using contraception had a desire to have a more effective method.

In Table 4 the group that opted for alternative methods of contraception preferred the hormonal contraception methods $5.4 \%$ and $1.4 \%$ preferred other long acting methods, the implants. $93.2 \%$ did not opt for alternative methods. Agrees to the report by United Nations Department of Economic and Social Affairs 
(UNDESA) (2015), indicates that Contraceptive use by type; Pills and injections are the most commonly used in Africa at $8.7 \%$ and $9.8 \%$, respectively. Intra Uterine Contraceptive Device (IUCD) utilization is at $3.8 \%$ while implants are at $2.3 \%$ and male condoms at $2.1 \%$.

In Table 5 68\% said that they were not given counseling services on PPIUCD insertion and the few who were counseled, it was done after delivery in postnatal ward $12.2 \%$, during antenatal period was $6.8 \%, 5.4 \%$ was counseled on admission, $5.4 \%$.

Table 2. Reasons why the respondents did not get PPIUCD insertion.

\begin{tabular}{cc}
\hline REASONS & PERCENTAGE \\
\hline I refused & 32.1 \\
not given information & 57.0 \\
I had a problem & 4.1 \\
service not offered & 4.1 \\
Others & 2.7 \\
\hline
\end{tabular}

Table 3. Client, provider and method related barriers.

\begin{tabular}{cc}
\hline BARRIERS & PERCENTAGE \\
\hline myths/misconceptions & 2.7 \\
Religion & 1.4 \\
attitude/delayed/poor service & 2.7 \\
bad experience/side effects & 2.7 \\
other alternative methods & 25.8 \\
not married therefore I don't need & 1.4 \\
N/A & 77.0 \\
\hline
\end{tabular}

Table 4. Preferred method of alternative contraception.

\begin{tabular}{cc}
\hline BARRIER & PERCENTAGE \\
\hline Hormonal & 5.4 \\
long acting & 1.4 \\
N/A & 93.2 \\
\hline
\end{tabular}

Table 5. Timing of counseling on contraception.

\begin{tabular}{cc}
\hline TIME COUNSELED & PERCENTAGE \\
\hline not counseled & 68.9 \\
during antenatal & 6.8 \\
on admission & 5.4 \\
after delivery & 12.2 \\
Others & 5.4 \\
\hline
\end{tabular}


Lack of confidence, training and experience on insertion of PPIUCD is evident in a study on midwives' views on PPIUCD [12] at ninewells hospital Dundee UK [15]. In other respects, lack of enough providers or shortage of staffs contributed to delayed services in a study on midwives' views on PPIUCD [12] at nine wells hospital Dundee U.K.

This contradicts to a study concerning barriers related to the method by Bola et al. [7] more than half of the women who had discontinued using contraception had a desire to have a more effective method. This could be due to past experience of failure of the method or the presence of side-effects.

\section{Conclusions and Recommendations}

The identified barriers to PPIUCD uptake are provider related which include non-provision of contraception services and untimely counseling for PPIUCD insertion. Method related barriers include alternative methods of contraception related to previous bad experience and side effects. Client related barriers include lack of information on PPIUCD, young age, low parity and unemployment.

The following recommendations were made based on the research findings.

1) From the findings of the study, young age, low parity and unemployment contributed to low uptake of PPIUCD. Sensitization on this method of family planning should target this group of mothers who are young aged, those with low parity and the unemployed. Lack of knowledge on the availability of PPIUCD services influenced low uptake. Reproductive health department should put community based strategies in place to create awareness of PPIUCD services in the hospital, given that lack of awareness is a key barrier to the uptake.

2) According to the results, either non-provision of the services or untimely counseling for the insertion contributed to the low uptake of PPIUCD services. The hospital administration should ensure that continuous education and job training are done to the providers. Staff motivation and staffing issues should be addressed for improvement of service delivery given that providers played a major role in low uptake.

3) From the findings of the study, properties and characteristics of family planning methods influenced uptake of PPIUCD services. An investigation of the effectiveness of the method in preventing pregnancy should be carried out. Side effects of alternative methods and their effects to the users should also be investigated.

\section{Conflicts of Interest}

The authors declare no conflicts of interest regarding the publication of this paper.

\section{References}

[1] Eltomy, M., Saboula, N. and Hussein, A. (2013) Barriers Affecting Utilization of 
Family Planning Services among Rural Egyptian Women. Eastern Mediterranean Health Journal, 19, 400-408. https://doi.org/10.26719/2013.19.5.400

[2] Ahmed, S., Li, Q., Liu, L. and Tsui, A.O. (2012) Maternal Deaths Averted by Contraceptive Use: An Analysis of 172 Countries. Lancet, 380, 111-125.

https://doi.org/10.1016/S0140-6736(12)60478-4

[3] World Health Organization (2018) Family Planning/Contraception. World Health Organization, Geneva.

[4] Dimoia, J.P. (2016) Counting Ones Allies: The Mobilization of Demography, Population and Family Planning. East Asian Science, Technology and Society, 10, 355-376. https://doi.org/10.1215/18752160-3682679

[5] Kumar, D., Kalia, M., Goel, N.K. and Sharma, M.K. (2016) Impact of Health Education on Unmet Needs of Contraception in Urban Slums of Chandigarh, India. International Journal of Reproduction, Contraception, Obstetrics and Gynaecology, 80, 17-20.

[6] Pauline, B., Carol, M., Eva, K. and Richard, M. (2016) The Influence of Religion and Ethnicity on Family Planning. Journal of Religion \& Health, 55, 1192-1205.

[7] Bola, L.S. (2017) Factors Influencing Contraceptive Use and Non-Use among Women of Advanced Reproductive Age. Journal of Health, Population and Nutrition, 36, 1. https://doi.org/10.1186/s41043-016-0077-6

[8] Rachel, L., Stein, F., Sarah, J. and Maricianah, O. (2013) Overcoming Barriers to Family Planning through Integration: Perspectives of HIV Positive Men in Nyanza Province, Kenya. AIDS Research and Treatment, Article ID: 861983, 8 p.

[9] Ahmed, Z., Nazlu, I., Khatun, M. and Mosiur, R. (2017) Prevalence and Determinants of Contraceptive Use among Employed and Unemployed Women in Bangladesh. International journal of MCH and AIDS, 5, 92-102.

[10] Sushila, K., Sanjaya, S. and Kumari, M. (2016) A Comparative Study of Postpartum Intrauterine Contraceptive Device Acceptance between Primiparous and Multiparous Women in a Tertiary Care Centre. International Journal of Reproduction, Contraception, Obstetrics and Gynecology, 5, 2304-2306.

[11] Ochako, R., Mbondo, M., Aloo, S., Kaimenyi, S., Thompson, R., Temmerman, M. and Kays, M. (2015) Barriers to Modern Contraceptive Uptake among Young Women in Kenya: A Qualitative Study. BMC Public Health, 15, 118. https://doi.org/10.1186/s12889-015-1483-1

[12] Cooper, M. and Lynch, P. (2015) A Survey of Midwives' Experience on PPIUCD. British Medical Journal, 93, 347-355.

[13] Babbie, E.R. (2013) Basics of Social Research. Thomson/Wadsworth, Belmont, CA.

[14] Nassiuma, D.K. (2000) Survey Sampling; Theory \& Methods. Nairobi University Press, Nairobi.

[15] Meru Teaching and Referral Hospital (2017) Records on PPIUCD Uptake. 


\section{Appendix 1}

QUESTIONNAIRE ON BARRIERS (FOR MOTHERS WITHOUT AN INSERTION)

Barriers to Immediate Post Partum Intra Uterine Contraceptive Device uptake among Mothers delivering at Meru Hospital.

Serial no.

IP no.

Circle the appropriate option in each question

SECTION A: Social demographic characteristics

1) What is your age group?
a) Below 15 years
b) $15-19$ years
c) $20-30$ years
d) Above 30 years

2) What is your education level?
a) None formal education
b) primary
c) Secondary
d) tertiary

3) What is your marital status?
a) Married
b) Separated/divorced
c) Widowed
d) single

4) What religious denomination do you belong?
a) Catholic
b) protestant
c) Muslim
d) Others, specify
e) None

5) Who do you live with?
a) Spouse
b) In-laws/own parents
c) A lone
d) Others, specify.

6) What is your current employment status?
a) salaried employment
b) unemployed
c) self-employment

SECTION B: Reproductive characteristics

7) When did you deliver?

a) Less than 12 hours ago

b) 12 - 24 hours ago 
c) 25 - 48 hours

d) More than 48 hours

8) Year of your previous delivery if any

a) Not applicable

b) Less than two years ago

c) 2 - 5 years

d) More than five years

9) Number of previous pregnancies (parity)
a) None
b) $1-3$
c) More than 3

10) When do you wish to have another pregnancy?
a) Not again
b) within two years from now
c) 2 - 5 years
d) more than 5 years
e) Others

SECTION C: Other factors that impede PPIUCD uptake (client, provider $\&$ method related)

11) When did you lastly hear or read about family planning?
a) less than 6 months ago
b) more than 6 months ago
c) can't remember
d) never heard

12)a) Why was the insertion of PPIUCD not done to you after this delivery?

i) I refused to consent for insertion

ii) I was not given information on PPIUCD insertion

iii) I had a problem therefore did not meet the insertion criteria

iv) I was informed and consented but service not offered to me

v) Others, specify

b) In case you refused to consent, why?

i) Fears and concerns of myths and misconceptions

ii) My husband and relatives opinion

iii) On the basis of my religion

iv) Cultural norms

v) Staff negative attitude, delayed and poor services

vi) Previous bad experience and side effects on this type of method

vii) Opting for other methods of family planning

viii) I am not married therefore no worry for family planning

ix) $\mathrm{N} / \mathrm{A}$

Others, specify

c) If opting for another method of family planning, which one?

i) Permanent e.g. tubal ligation

ii) Hormonal contraception e.g. pills, injection 
iii) Barrier methods e.g. condoms

iv) Other long acting reversible methods e.g. implants

v) Natural method

vi) Others, specify

vii) $\mathrm{N} / \mathrm{A}$

13)In case you were not given any information on PPIUCD insertion, why didn't you ask for the services?

a) I had no knowledge whether such services exist

b) I didn't like their services and attitude

c) I had doubts on competence and experience of the service providers

d) Others, specify.

e) $\mathrm{N} / \mathrm{A}$

14) When were you counseled for PPIUCD insertion?

a) Not counseled

b) During antenatal period

c) On admission while in labour

d) After delivery

e) Others, specify

15) What are your perceptions about PPIUCD as a method of family planning?

a) it is not effective

b) It is very effective

c) Interferes with sex

d) Can cause medical and gynecological problems

e) Bad side effects

f) painful

\section{Appendix 2}

INTERVIEW SCHEDULE ON BARRIERS (FOR MOTHERS WITHOUT AN INSERTION)

Determinants of Immediate Post Partum IntraUterine Contraceptive Device uptake among Mothers delivering at Meru Hospital

Serial no.

IP no

Answer all the questions below

1) Tell me briefly what you know about family planning generally.

2) What do you know about PPIUCD specifically and where did you get the information from?

3) Why was the insertion of PPIUCD not done to you after this delivery?

4) What are your perceptions about PPIUCD services at Meru hospital and what others tell you about PPIUCD?

5) What method of family planning do you prefer and why?

6) What method have you been using before? 